\title{
NUMERICAL METHODS FOR OPTIMAL CONTROL BASED SCHEMES FOR VOLATILITY CALIBRATION AND ALGORITHMIC TRADING
}

\author{
Deepak Kumar \\ Department of Economics \\ Indian Institute of Technology Kanpur \\ Kanpur-208016, India \\ E-mail: kdeepak.iitk@gmail.com
}

\section{KEYWORDS}

Stochastic Control, Mathematical Finance, Finite Difference methods .

\begin{abstract}
Numerical schemes for inverse problems like volatility estimation or learning market neutral density are of prime importance for financial planning. Recent advances in numerical techniques like finite difference solvers based on parallel computation, Monte Carlo for spectral computations has led to formulation of many approximations based on these methods for financial instruments. This paper surveys two very important problems in finance e.g. volatility calibration and timing of order placing in automatic trading with finite difference discretization schemes. The methods for volatility calibration are illustrated using convergence of Euler Pontryagin approximation for a simplistic model with diffusion price process and then later on more general price process have also been shown to fit into these frameworks through similarity of their adjoint equations. The control approach in algorithmic trading has been done through viscosity solutions and Lax Friedrich numerical schemes.
\end{abstract}

\section{INTRODUCTION}

Volatility of the underlying asset is a crucial parameter in the Black-Scholes formula and the Black-Scholes equation for pricing general options as these are sensitive to volatility and investors like to anticipate future price of the assets concerned. The volatility is in general unpredictable which renders estimation of volatility difficult. However, the options market "knows" it. Obtaining and analyzing prices of a number of options on a given underlying asset with various strike prices and expiration dates helps in a way that we can implicitly determine volatility by using measured market values of options on the considered asset. The canonical technique of Dupire's method for estimating volatility can also be used but is typically ill posed. So we convert the implied volatility determination problem to a terminal state observation problem for a parabolic equation and the latter being a a typical inverse problem, enables us to find a well-posed algorithm for it in the framework of optimal control theory. Thus the problem is changed to an optimal control problem with the volatility parameter as control variable. Similarity of other models with general price processes with Dupire's model for a simplistic model is shown through similarity of their adjoint equations and later on the paper gives finite difference based approximations for Dupire's model which can also be applied to models with general price process.

In words of (Bouchard et al. 2010) "Trading algorithms are widely used by financial agents for high frequency intra-day trading purposes, e.g. for "statistical arbitrage" or for the execution of large orders by brokers in order to make profit of good prices. In both cases, large size of the portfolios which are handeled by a limited number of traders and the fact that the orders have to be executed very quickly justify and at times necessitate the use of robots. These algorithms relate to global optimization problems and are run without interruption on the whole trading period. Brokers first split the global number of assets to be bought or sold into slices. And then use robots to execute these sequentially. Execution of every new slice either requires a new robot or calls for tuning the parameters of the algorithm taking into account the evolving market conditions (which can actually also be viewed as changing the parameters of a single robot, at least from the mathematical point of view). Thus in practice the trader has a bunch of trading algorithms which helps him decide how to slice the order, time of starting and finishing the launch and values of the parameters. The existence of a minimal time period for each algorithm is required because the trader can not monitor all the algorithms running for different purposes simultaneously and it also is not feasible to launch an algorithm for less than, say, one second. This paper aims at providing a decision tool for traders given the above described practical situation." The paper presents the framework for the optimal control of trading algorithms: i.e. how the problem can be converted into a finite difference scheme using control theoretic framework based on the above model.

\section{VOLATILITY CALIBRATION PROBLEM}

Let's consider a simplistic model where stochastic process of the asset price movement under the riskneutral measure is 


$$
\frac{\mathrm{dS}}{\mathrm{S}}=(\mathrm{r}-\mathrm{q}) \mathrm{dt}+\sigma(\mathrm{S}, \mathrm{t}) \mathrm{dW}_{\mathrm{t}}
$$

where $W$ denotes Brownian motion.

Correspondingly, the Black-Scholes equation becomes

$$
\frac{\partial \mathrm{C}}{\partial \mathrm{t}}+\frac{1}{2} \sigma^{2}(\mathrm{~S}, \mathrm{t}) \mathrm{S}^{2} \frac{\partial^{2} \mathrm{C}}{\partial \mathrm{S}^{2}}+(\mathrm{r}-\mathrm{q}) \mathrm{S} \frac{\partial \mathrm{C}}{\partial \mathrm{S}}-\mathrm{rC}=0 .
$$

In general, this type of problem has no explicit solution. It must be solved by numerical methods. With the improved price model of the underlying asset, we ask a question: how can we determining the volatility of an underlying asset price from its option price quotes in the options market i.e. at $\mathrm{t}=\mathrm{t}_{0}, \mathrm{~S}=\mathrm{S}_{0}$, if

$$
\mathrm{C}\left(\mathrm{S}_{0}, \mathrm{t}_{0} ; \sigma, \mathrm{K}_{\mathrm{k}}, \mathrm{T}_{1}\right)=\mathrm{C}_{\mathrm{k}, 1}(\mathrm{k}=1, \ldots, \mathrm{m}, \mathrm{l}=1, \ldots, \mathrm{n})
$$

are given and we have to find the volatility function

$$
\sigma=\sigma(\mathrm{S}, \mathrm{t}) \text {. }
$$

So the problem is precisely : Let $\mathrm{C}=\mathrm{C}(\mathrm{S}, \mathrm{t} ; \sigma, \mathrm{K}, \mathrm{T})$ be a call option price, satisfying

$$
\left\{\begin{array}{c}
\frac{\partial \mathrm{C}}{\partial \mathrm{t}}+\frac{1}{2} \sigma^{2}(\mathrm{~S}, \mathrm{t}) \mathrm{S}^{2} \frac{\partial^{2} \mathrm{C}}{\partial \mathrm{S}^{2}}+(\mathrm{r}-\mathrm{q}) \mathrm{S} \frac{\partial \mathrm{C}}{\partial \mathrm{S}}-\mathrm{rC}=0, \\
(0 \leq \mathrm{S}<\infty, 0 \leq \mathrm{t}<\mathrm{T}) \\
\mathrm{C}(\mathrm{S}, \mathrm{T})=(\mathrm{S}-\mathrm{K})^{+} . \quad(0 \leq \mathrm{S}<\infty)
\end{array}\right.
$$

and suppose that at $t=t^{*}\left(0 \leq \mathrm{t}^{*} \leq \mathrm{T}_{1}\right), S=S^{*}$

$$
\mathrm{v}\left(\mathrm{S}^{*}, \mathrm{t}^{*} ; \sigma, \mathrm{K}, \mathrm{T}\right)=\mathrm{F}(\mathrm{K}, \mathrm{T}) \quad\left(0<\mathrm{K}<\infty, \mathrm{T}_{1} \leq \mathrm{T} \leq \mathrm{T}_{2}\right)
$$

is given and we have to find

$$
\sigma=\sigma(S, t),\left(0 \leq S<\infty, T_{1} \leq t \leq T_{2}\right)
$$

\section{Dupire Solution}

Let $\mathrm{C}=\mathrm{C}(\mathrm{S}, \mathrm{t} ; \mathrm{K}, \mathrm{T})$ be a European call option price and then from Dupire's method (Achdou and Pironeau 2005; Dupire 1997; Gatheral 2006) we will get

$$
\left\{\begin{array}{c}
-\frac{\partial \mathrm{C}}{\partial \mathrm{T}}+\frac{1}{2} \mathrm{~K}^{2} \sigma^{2}(\mathrm{~K}, \mathrm{~T}) \frac{\partial^{2} \mathrm{C}}{\partial \mathrm{K}^{2}}-(\mathrm{r}-\mathrm{q}) \mathrm{K} \frac{\partial \mathrm{C}}{\partial \mathrm{K}}-\mathrm{qC}=0 . \\
(0 \leq \mathrm{K}<\infty, \mathrm{t} \leq \mathrm{T}) \\
\left.\mathrm{C}\right|_{\mathrm{T}=\mathrm{t}}=(\mathrm{S}-\mathrm{K})^{+} .(0 \leq \mathrm{K}<\infty)
\end{array}\right.
$$

$$
\begin{gathered}
\sigma(K, T)=\sqrt{\frac{\frac{\partial \mathrm{C}}{\partial \mathrm{T}}+(\mathrm{r}-\mathrm{q}) \mathrm{K} \frac{\partial \mathrm{C}}{\partial \mathrm{K}}+\mathrm{qC}}{\frac{1}{2} \mathrm{~K}^{2} \frac{\partial^{2} \mathrm{C}}{\partial \mathrm{K}^{2}}}} \\
{\left[\mathrm{C}_{\mathrm{T}}-\frac{1}{2} \sigma^{2} \mathrm{~K}^{2} \mathrm{C}_{\mathrm{kk}}-(\mathrm{r}-\mathrm{q}) \mathrm{KC}_{\mathrm{k}}-\mathrm{C}=0\right]}
\end{gathered}
$$

Let's call (5) as the adjoint equation and we will see the similarity of this equation with adjoint equation of other models with different stochastic processes which are illustrated below.

\section{Calibration with Stochastic volatility model with \\ Poisson process}

Consider the price process $\mathrm{S}$ whose dynamics under the pricing measure $\mathrm{P}$ is given by: where $\mathrm{B}$ is a Brownian motion and $\mathrm{N}$ a Poisson random measure on $[0, \mathrm{~T}] \times \mathrm{R}$ with compensator $v$ and $\mathrm{N}$ is the associated compensated random measure. Assume

$$
\int_{y>1} e^{2 y} v(d y)<\infty \text { and } \sigma(., .) \text { is bounded }
$$

The price dynamics is

$$
\mathrm{S}_{\mathrm{t}}=\mathrm{S}_{0}+\int_{0}^{\mathrm{T}} \mathrm{r}_{\mathrm{t}} \mathrm{S}_{\mathrm{t}_{-}} \mathrm{dt}+\int_{0}^{\mathrm{T}} \mathrm{S}_{\mathrm{t}-} \sigma\left(\mathrm{t}, \mathrm{S}_{\mathrm{t}-}\right) \mathrm{d} \mathrm{B}_{\mathrm{t}}+\int_{0}^{\mathrm{T}} \int_{-\infty}^{\infty} \mathrm{S}_{\mathrm{t}-}\left(\mathrm{e}^{\mathrm{y}}-1\right) \mathrm{N}(\mathrm{dt}, \mathrm{dy})
$$

Then the equation can be reduced to

$$
\left\{\begin{array}{c}
\frac{\partial \mathrm{C}_{\mathrm{t}_{0}}}{\partial \mathrm{T}}=-\mathrm{r}(\mathrm{T}) \mathrm{K} \frac{\partial \mathrm{C}_{\mathrm{t}_{0}}}{\partial \mathrm{T}}+\frac{1}{2} \mathrm{~K}^{2} \sigma^{2}(\mathrm{~K}, \mathrm{~T}) \frac{\partial^{2} \mathrm{C}_{\mathrm{t}_{0}}}{\partial \mathrm{K}^{2}} \\
+\int_{\mathrm{R}} \mathrm{v}(\mathrm{dz}) \mathrm{e}^{\mathrm{z}}\left\{\mathrm{C}_{\mathrm{t}_{0}}\left(\mathrm{~T}, \mathrm{Ke}^{-\mathrm{z}}\right)-\mathrm{C}_{\mathrm{t}_{0}}(\mathrm{~T}, \mathrm{~K})-\mathrm{K}\left(\mathrm{e}^{-\mathrm{z}}-1\right) \frac{\partial \mathrm{C}_{\mathrm{t}}}{\partial \mathrm{K}}\right. \\
(\mathrm{T}, \mathrm{K}) \in\left[\mathrm{t}_{0}, \infty\right) \otimes(0, \infty) \\
\mathrm{C}_{\mathrm{t}_{0}}\left(\mathrm{t}_{0}, \mathrm{~K}\right)=\left(\mathrm{S}_{\mathrm{t}_{0}}-\mathrm{K}\right)^{+} . \quad(0 \leq \mathrm{K}<\infty)
\end{array}\right.
$$

Calibration of Stochastic volatility model with random jumps

The price dynamics is

$$
\mathrm{S}_{\mathrm{t}}=\mathrm{S}_{0}+\int_{0}^{\mathrm{T}} \mathrm{r}_{\mathrm{t}} \mathrm{S}_{\mathrm{t}-} \mathrm{dt}+\int_{0}^{\mathrm{T}} \mathrm{S}_{\mathrm{t}-} \delta_{\mathrm{t}} \mathrm{d} \mathrm{W}_{\mathrm{t}}+\int_{0-\infty}^{\mathrm{T}} \int_{-\infty}^{\infty} \mathrm{S}_{\mathrm{t}-}\left(\mathrm{e}^{\mathrm{y}}-1\right) \mathrm{M}(\mathrm{dt}, \mathrm{dy})
$$

Where $r(t)$ is the discount rate, $\delta_{t}$ is the spot volatility process and $\mathrm{M}$ is a compensated random measure with compensator

$$
\mu(\omega ; \mathrm{dt} d y)=m(\omega ; \mathrm{t} d y) d t
$$

Let's make the assumption

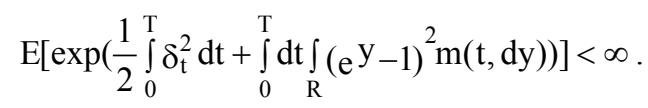

then under above assumption the call option price $(\mathrm{T} ; \mathrm{K})$ $\rightarrow \mathrm{C}_{\mathrm{t}}(\mathrm{T} ; \mathrm{K})$, as a function of maturity and strike, is a solution (in the sense of distributions) of the partial integro-differential equation: 


$$
\left\{\begin{aligned}
\frac{\partial \mathrm{C}_{\mathrm{t}_{0}}}{\partial \mathrm{T}}=-\mathrm{r}(\mathrm{T}) \mathrm{K} & \frac{\partial \mathrm{C}_{\mathrm{t}_{0}}}{\partial \mathrm{T}}+\frac{1}{2} \mathrm{~K}^{2} \sigma^{2}(\mathrm{~K}, \mathrm{~T}) \frac{\partial^{2} \mathrm{C}_{\mathrm{t}_{0}}}{\partial \mathrm{K}^{2}} \\
& +\int_{0}^{\infty} \mathrm{y} \frac{\partial^{2} \mathrm{C}_{\mathrm{t}_{0}}}{\partial \mathrm{K}^{2}}(\mathrm{~T}, \mathrm{dy}) \chi_{\mathrm{T}, \mathrm{y}}\left(\ln \left(\frac{\mathrm{K}}{\mathrm{y}}\right)\right) \\
(\mathrm{T}, \mathrm{K}) \in\left[\mathrm{t}_{0}, \infty\right) \otimes(0, \infty) & \\
\mathrm{C}_{\mathrm{t}_{0}}\left(\mathrm{t}_{0}, \mathrm{~K}\right) & =\left(\mathrm{S}_{\mathrm{t}_{0}}-\mathrm{K}\right)^{+} . \quad(0 \leq \mathrm{K}<\infty)
\end{aligned}\right.
$$

We can see the similarity of (7) and (8) to (5). For such examples one is referred to (Achdou 2005; Gatheral 2006).

\section{Computational Problems with Dupire's Model}

Suppose that at $t=t^{*}, S=S^{*}$ we can get from the options market the option price quotes with various strike prices and expiration dates, i.e. if we know the function $\mathrm{F}(\mathrm{K}, \mathrm{T})=\mathrm{C}\left(\mathrm{S}^{*}, \mathrm{t}^{*} ; \mathrm{K}, \mathrm{T}\right)$, then we can calculate $\sigma(\mathrm{K}, \mathrm{T})$ by (6) however, this algorithm is not robust to the real data and is thus not reliable. In fact, for a given $F(K, T)$, in order to calculate $\sigma(K, T)$ by (6), we need to calculate the derivatives $\mathrm{F}_{\mathrm{KK}}, \mathrm{F}_{\mathrm{K}}$ and $\mathrm{F}_{\mathrm{T}}$. But a small error in $\mathrm{F}$ can result in big changes in its derivatives, especially in its second derivatives. Therefore the algorithm to compute $\sigma(\mathrm{K}, \mathrm{T})$ by $(6)$ is illposed. In general, $F(K, T)$ is given on a set of discrete points $\left\{\left(\mathrm{K}_{\mathrm{k}}, \mathrm{T}_{1}\right)\right\}(\mathrm{k}=1, \ldots, \mathrm{m}, \mathrm{l}=1, \ldots, \mathrm{n})$. Thus interpolation or extrapolation technique would be required to obtain a continuous function $\mathrm{F}(\mathrm{K}, \mathrm{T})$ in the domain $\left(0 \leq \mathrm{K}<\infty, \mathrm{T}_{1} \leq \mathrm{T} \leq \mathrm{T}_{2}\right)$ from the values at discrete points. However, naive interpolation and extrapolation tend to incur irregularity and instability in the solution $\sigma(\mathrm{K}, \mathrm{T})$. A more robust calibration method is hence needed. Although Dupire method is not practical, nevertheless, we can follow its idea in solving this ill-posed problem. That is, we still want to reduce the implied volatility determination problem to a terminal state observation problem for a parabolic equation. Since the latter is a typical inverse problem, we can always find a well-posed algorithm for it. We convert the implied volatility function determination problem to a terminal state observation problem so that in the framework of optimal control theory we could find a well posed numerical iteration.

\section{ALGORITHMIC TRADING CONTROL PROBLEM}

Following the model (Bouchard et al. 2010) a control policy of the trading algorithm is described by a non- decreasing sequence of stopping times $\left(\tau_{\mathrm{i}}\right)_{\mathrm{i} \geq 1},[\delta, \infty) \times E$ valued random value $\left(\delta_{\mathrm{i}}, \varepsilon_{\mathrm{i}}\right)_{\mathrm{i} \geq 1}$. The stopping times $\tau_{\mathrm{i}}$ describe the times at which an order is given to the algorithm, $\varepsilon_{\mathrm{i}}$ is the value of the parameters with which the algorithm is run and $\delta_{\mathrm{i}}$ the length of the period (latency period) during which it is run with the value $\varepsilon_{\mathrm{i}}$. The set $E$ is a compact subset of $\mathrm{R}^{\mathrm{d}}$, which represents the possible values of the parameters, the quantity $0 \leq$ $\delta^{\prime} \leq T$ denotes the minimum length of the time period during which the algorithm can be run. At time it $t \epsilon\left[\tau_{\mathrm{i}}\right.$, $\tau_{\mathrm{i}}+\delta_{\mathrm{i}}$ ) the value of the parameter of the trading algorithm is denoted by $v_{\mathrm{t}}$. For $t \epsilon A\left(\left[\tau_{\mathrm{i}}, \delta_{\mathrm{i}}\right)_{\mathrm{i} \geq 1}\right)$

$$
\mathrm{t} \in \mathrm{A}\left(\left[\tau_{\mathrm{i}}, \delta_{\mathrm{i}}\right)_{\mathrm{i} \geq 1}\right):=\mathrm{R}_{+} \backslash\left(\bigcup_{\mathrm{i} \geq 1}\left[\tau_{\mathrm{i}}, \tau_{\mathrm{i}}+\delta_{\mathrm{i}}\right)\right)
$$

set $v_{\mathrm{t}}=\varpi \quad$ where $\varpi \epsilon R^{\mathrm{d}} \backslash E$. So values of the parameters of the trading algorithm $v_{t}$ can be written as

$$
v_{\mathrm{t}}=\varpi 1_{\mathrm{A}\left(\left[\tau_{\mathrm{i}}, \delta_{\mathrm{i}}\right)_{\mathrm{i} \geq 1}\right)}+\sum_{\mathrm{i} \geq 1} \varepsilon_{\mathrm{i}} \mathbf{1}_{\left.\mathrm{i} \in \tau_{\mathrm{i}}, \tau_{\mathrm{i}}+\delta_{\mathrm{i}}\right)}, \quad \mathrm{t} \in[0, \mathrm{~T}]
$$

In the following, let's denote by $S$ the set of adapted processes $v$ that can be written in the above form for some sequence of stopping times $\left(\tau_{\mathrm{i}}\right)_{\mathrm{i} \geq 1}$ and of $[\delta, \infty) \times$ $E$ valued random variables $\left(\delta_{\mathrm{i}}, \varepsilon_{\mathrm{i}}\right)_{\mathrm{i} \geq 1},\left(\tau_{\mathrm{i}}^{v}, \delta_{\mathrm{i}}^{v}, \varepsilon_{\mathrm{i}}^{v}\right)_{\mathrm{i} \geq 1}$ is the sequence associated to $v \in S$.

Given some initial data $(t, x) \in[0, \mathrm{~T}] \times \mathrm{R}^{\mathrm{d}}$ the output of the trading algorithm associated to some control policy $v \in S$ is defined as the strong solution $\mathrm{X}_{\mathrm{t}, \mathrm{x}}^{v}$ on $[0 ; \mathrm{T}]$ of the stochastic differential equation

$$
X_{t, X}^{v}=x+\mathbf{1}_{s \geq t}\left(\begin{array}{r}
\int_{t}^{s} b\left(X_{t, x}^{v}(r), v_{r}\right) d r+\int_{t}^{s} b\left(X_{t, x}^{v}(r), v_{r}\right) d W_{r} \\
\sum_{i \geq 1} \beta\left(X_{t, x}^{v}\left(\tau_{i}^{v}-\right), \delta_{i}^{v}, \varepsilon_{I}^{v}\right) \mathbf{1}_{t<\tau_{i}^{v} \leq s}
\end{array}\right)
$$

where $v_{\mathrm{t}}=\varpi$ means that the algorithm is not running at time t. The aim of the controller is to maximize the expected value of the gain functional $\Delta_{\mathrm{t}+\delta}^{v}$

$$
\begin{aligned}
& v \in \mathrm{S} \mapsto \Pi_{\mathrm{t}, \mathrm{x}}(v):=\mathrm{g}\left(\mathrm{X}_{\mathrm{t}, \mathrm{x}}^{v}(\mathrm{~T})+\sum_{\mathrm{i} \geq 1} \mathrm{f}\left(\mathrm{X}_{\mathrm{t}, \mathrm{x}}^{v}\left(\tau_{\mathrm{i}}^{v}+\delta_{\mathrm{i}}^{v}-\right), \varepsilon_{\mathrm{I}}^{v}\right)\right. \\
& \begin{array}{c}
S_{\mathrm{t}, \delta, \mathrm{e}}=\quad v \in S: v_{\mathrm{s}}=\mathrm{e} ; s \in\left[\tau, \tau_{+} \delta\right) \& \Delta_{\mathrm{t}+\delta}^{v}=0 \\
v \in S: v_{\mathrm{t}}=\varpi
\end{array} \\
& \mathrm{V}(\mathrm{t}, \mathrm{x}, \delta, \mathrm{e}):=\underbrace{\sup _{1}}_{v \in \mathrm{s}_{\mathrm{t}, \delta ; \mathrm{e}}^{\mathrm{a}}} \mathrm{E}\left[\Pi_{\mathrm{t}, \mathrm{x}}(v)\right]
\end{aligned}
$$

where $(\delta, \mathrm{e}) \epsilon \mathrm{R}_{+} \times E$ denotes the initial state of the remaining latency time and value of the parameters.

Let's consider the case where the aim of the controller is to sell a number $\mathrm{Q}_{0}$ of one stock $\mathrm{S}$ between 0 and $\mathrm{T}>0$. We denote by $\mathrm{V}_{\mathrm{t}}$ the global volume instantaneously traded on the market at time $t$. The 
dynamics of $(\mathrm{S}, \mathrm{V})$ is given by the strong solution of the SDE

$$
\begin{gathered}
\mathrm{S}_{\mathrm{t}}=\mathrm{S}_{0}+\int_{0}^{\mathrm{t}} \mu_{\mathrm{S}}\left(\mathrm{r}, \mathrm{S}_{\mathrm{r}}, \mathrm{V}_{\mathrm{r}}\right) \mathrm{dr}+\int_{0}^{\mathrm{t}} \sigma_{\mathrm{S}}\left(\mathrm{r}, \mathrm{S}_{\mathrm{r}}, \mathrm{V}_{\mathrm{r}}\right) \mathrm{dW}_{\mathrm{r}} \\
\mathrm{V}_{\mathrm{t}}=\mathrm{V}_{0}+\int_{0}^{\mathrm{t}} \mu_{\mathrm{V}}\left(\mathrm{r}, \mathrm{S}_{\mathrm{r}}, \mathrm{V}_{\mathrm{r}}\right) \mathrm{dr}+\int_{0}^{\mathrm{t}} \sigma_{\mathrm{V}}\left(\mathrm{r}, \mathrm{S}_{\mathrm{r}}, \mathrm{V}_{\mathrm{r}}\right) \mathrm{dW}_{\mathrm{r}},
\end{gathered}
$$

where $W$ denotes a two dimensional standard Brownian motion, and $\left(\mu_{\mathrm{S}}, \sigma_{\mathrm{S}}, \mu_{\mathrm{V}}, \sigma_{\mathrm{V}}\right)$ are Lipschitz continuous. It is implicitly assumed that the above SDE has nonnegative solutions whatever the initial conditions are. A control $v \in S$ is identified to a sequence $\left(\tau_{\mathrm{i}}^{v} \delta_{\mathrm{i}}^{v} \varepsilon_{\mathrm{i}}^{v}\right)_{\mathrm{i}>1} \in$ $S$. Here $\varepsilon_{\mathrm{i}}^{v}$ stands for the intensity at which the stocks are bought, i.e. the algorithm buys a number $\varepsilon_{\mathrm{i}}^{\mathrm{v}} \mathrm{dt}=v_{\mathrm{t}} 1_{v_{\mathrm{t}} \neq \varpi} \mathrm{dt} \quad$ of $\quad$ stocks on $[t, t+d t], t \in\left[\tau_{i}^{v}, \tau_{i}^{v}+\delta_{i}^{v}\right)$. The dynamics of the remaining number of stocks to he bought before $T$ is thus given by:

$$
\mathrm{Q}_{\mathrm{t}}^{\mathrm{v}}=\mathrm{Q}_{0}-\int_{0}^{\mathrm{t}} \mathrm{q}\left(\mathrm{v}_{\mathrm{s}}\right) \mathrm{ds}
$$

where $q$ is now defined as $\mathrm{q}(\mathrm{e})=\mathrm{cl}_{\mathrm{e} \neq \omega}$. It follows that the cumulated wealth's dynamic is

$$
\mathrm{Y}_{\mathrm{t}}^{\mathrm{v}}=0+\int_{0}^{\mathrm{t}} \overline{\mathrm{S}}_{\mathrm{r}} \mathrm{q}\left(\mathrm{v}_{\mathrm{r}}\right) \mathrm{dr}=0+\int_{0}^{\mathrm{t}}\left(\mathrm{S}_{\mathrm{r}}+\eta\left(\mathrm{v}_{\mathrm{r}}, \mathrm{S}_{\mathrm{r}}, \mathrm{V}_{\mathrm{r}}\right)\right) \mathrm{q}\left(\mathrm{v}_{\mathrm{r}}\right) \mathrm{dr}
$$

where $\eta$ is a given market impact function.

If the number $Q_{0}$ of shares is not liquidated at time $T$ the remaining part $Q_{T}^{v}$ is instantaneously bought on the market at the price $S_{T}+c\left(Q_{T}^{v}, S_{T}, V_{T}\right)$ for some Lipschitz continuous function $c$. The total cost after the final transaction is thus given by:

$$
\mathrm{Y}_{\mathrm{T}}^{\mathrm{v}}+\left(\mathrm{S}_{\mathrm{T}}+\mathrm{c}\left(\mathrm{Q}_{\mathrm{T}}^{\mathrm{v}}, \mathrm{S}_{\mathrm{T}}, \mathrm{V}_{\mathrm{T}}\right)\right)\left(\mathrm{Q}_{\mathrm{T}}^{\mathrm{v}}\right)^{+}
$$

The aim of the controller is to minimize the expectation of the quantity

$$
1\left(\mathrm{Y}_{\mathrm{T}}^{\mathrm{v}}+\left(\mathrm{S}_{\mathrm{T}}+\mathrm{c}\left(\mathrm{Q}_{\mathrm{T}}^{\mathrm{v}}, \mathrm{S}_{\mathrm{T}}, \mathrm{V}_{\mathrm{T}}\right)\right)\left(\mathrm{Q}_{\mathrm{T}}^{\mathrm{v}}\right)^{+}\right)
$$

for some convex function $l$ satisfying regularity conditions.

\section{OPTIMAL CONTROL THEORETIC APPROACH}

\section{Control Approach to Volatility Calibration}

Let's consider an open set $\Omega \subset R^{n}$ and let $V$ be some Hilbert space of functions on $\Omega$ considered as a subspace of $L^{2}(\Omega)$ with its usual inner product. For a given cost functional $h: V \times V \rightarrow R: \mathrm{V} \mathrm{x} \mathrm{V \rightarrow R}$, the optimal control problem consists of finding

$$
\inf _{\sigma: \Omega \times[0, \hat{T}] \rightarrow R} \int_{0}^{\hat{T}} h(\varphi, \sigma) d t
$$

where $\varphi: \Omega \times[0, \hat{T}] \rightarrow R \quad$ is the solution to the differential equation

$$
\varphi_{\mathrm{t}}=\mathrm{f}(\varphi, \mathrm{t} ; \sigma)
$$

with some given initial function $\varphi(., 0)=\varphi^{0}$. For each choice of $\sigma$ it is a function $\mathrm{f}: \mathrm{V} \times[0, \hat{\mathrm{T}}] \rightarrow \mathrm{R} . \varphi_{t}$ denotes the partial derivative with respect to $t$. We refer to $\sigma$ as the control and the minimizer of (13), if it exists, is called the optimal control. We assume that $\sigma$ takes values in some compact set $B \subset R$. Let the value function $U$ be defined as:

$$
\begin{array}{r}
\mathrm{U}(\phi, \tau)=\inf _{\sigma: \Omega \times[\tau, \mathrm{T}] \rightarrow \mathrm{B}}\left\{\int_{\tau}^{\mathrm{T}} \mathrm{h}(\varphi, \sigma) \mathrm{dt} \| \varphi_{\mathrm{t}}=\mathrm{f}(\varphi, \mathrm{t} ; \sigma)\right. \\
\forall \mathrm{t} ; \tau<\mathrm{t}<\mathrm{T}, \varphi(\cdot, \tau)=\phi \in \mathrm{V}\}
\end{array}
$$

The value function $U$ solves the non-linear HamiltonJacobi-Bellman equation

$$
\mathrm{U}_{\mathrm{t}}+\mathrm{H}\left(\mathrm{U}_{\phi}, \phi\right)=0, \quad \mathrm{U}(\phi, \mathrm{T})=0
$$

where $\mathrm{H}: \mathrm{V} \times \mathrm{V} \rightarrow \mathrm{R}$ is the Hamiltonian associated to the above optimal control problem

$$
\mathrm{H}(\lambda, \varphi)=\inf _{\mathrm{a}: \Omega \rightarrow B}\{<\lambda, \mathrm{f}(\varphi, \mathrm{a})>+\mathrm{h}(\varphi, \mathrm{a})\}
$$

The method of characteristics associated to (15) yields the Hamiltonians system

$$
\begin{gathered}
\varphi_{\mathrm{t}}=\mathrm{H}_{\lambda}(\varphi, \lambda), \lambda_{\mathrm{t}}=-\mathrm{H}_{\varphi}(\varphi, \lambda) . \\
\varphi(\cdot, 0)=\varphi^{0}, \lambda(\cdot, \mathrm{T})=0
\end{gathered}
$$

where $\mathrm{H}_{\lambda}$ and $\mathrm{H}_{\varphi}$ denote the Gateaux-derivatives of $\mathrm{H}$ w.r.t. $\lambda$ and $\varphi$ respectively. The unknown quantity is the local volatility function $\sigma=\sigma(\mathrm{t}, \mathrm{S})$. Hence the problem of calibrating $\sigma$ from option prices can he formulated as an optimal control problem.

Suppose that $\mathrm{C}_{\mathrm{m}}=\mathrm{C}_{\mathrm{m}}(\mathrm{T}, \mathrm{K})$ are call options priced in the market, for different strikes $K \geq 0$ and maturities $0 \leq T \leq \hat{T}$. We wish to the determine the control $\sigma$ minimizing

$$
\begin{gathered}
\min _{\sigma} \int_{0}^{\hat{T}} \int_{\mathrm{R}+}\left(\mathrm{C}-\mathrm{C}_{\mathrm{m}}\right)^{2} \mathrm{dTdK} \\
\mathrm{C}_{\mathrm{T}}=\Phi_{1}(\mathrm{C})+\sigma^{2} \Phi_{2}(\mathrm{C}) \\
\mathrm{C}(\mathrm{K}, 0)=\max (\mathrm{S}-\mathrm{K}, 0) \mathrm{C}(0, \mathrm{~T})=\mathrm{S}
\end{gathered}
$$

It is also assumed that for all $T$ and $K, \sigma \in[\sigma \min , \sigma \max ]$. The problem as stated here is typically ill-posed as the solution often is very sensitive small changes in $C_{m}$.

\section{Discretized Hamiltonian}

Discrete Version of (17) 


$$
\begin{gathered}
\min _{\sigma} \int_{0}^{\hat{T}} \Delta \mathrm{K} \sum_{\mathrm{i}}\left(\mathrm{C}-\mathrm{C}_{\mathrm{m}}\right)_{\mathrm{i}}^{2} \mathrm{dT} \\
\left(\mathrm{C}_{\mathrm{i}}\right)_{\mathrm{T}}=\mathrm{D}_{\mathrm{i}}^{1}(\mathrm{C})+\sigma^{2} \mathrm{D}_{\mathrm{i}}^{2}(\mathrm{C})\left(\mathrm{C}_{\mathrm{i}}\right)_{0}=\max (\mathrm{S}-\mathrm{i} \Delta \mathrm{K}, 0)
\end{gathered}
$$

where $D^{l}$ and $D^{2}$ are finite difference operators associated with $\phi^{1}$ and $\phi^{2}$.

$$
\mathrm{D}_{\mathrm{i}}^{1} \mathrm{C}=\frac{\mathrm{C}_{\mathrm{i}+1}-\mathrm{C}_{\mathrm{i}-1}}{2 \Delta \mathrm{K}} \mathrm{D}_{\mathrm{i}}^{2} \mathrm{C}=\frac{\mathrm{C}_{\mathrm{i}+1}-\mathrm{C}_{\mathrm{i}-1}}{\Delta \mathrm{K}^{2}}
$$

We define the discrete Hamiltonian as

$$
\mathrm{H}(\lambda, \mathrm{C})=\Delta \mathrm{K} \sum_{\mathrm{i}=1}^{\mathrm{M}-1}\left\{\min _{\sigma_{\mathrm{i}}} \lambda_{\mathrm{i}}\left[\left(\mathrm{D}^{1} \mathrm{C}\right)_{\mathrm{i}}+\sigma_{\mathrm{i}}\left(\mathrm{D}^{2} \mathrm{C}\right)_{\mathrm{i}}\right]+\left(\mathrm{C}-\mathrm{C}_{\mathrm{m}}\right)_{\mathrm{i}}^{2}\right\}
$$

Since $H$ is not differentiable generally, we need to to regularize it in order for (15) to be sensible. There are different regularization schemes and the choice depends on the problem and we contend herewith Tikhonov regularization. See (Bouchouev and Isakov1997; Sandberg and Szepessy 2006) for different regularization schemes related to different problems. We construct a regularization of the Hamiltonian with appropriate function $s$ and its regularized version $s_{\delta}$ which are described below.

$$
\begin{gathered}
\mathrm{H}(\lambda, \mathrm{C})=\Delta \mathrm{K} \sum_{\mathrm{i}=1}^{\mathrm{M}-1}\left\{\mathrm{~s}\left(\lambda, \mathrm{D}^{1} \mathrm{C}, \mathrm{D}^{2} \mathrm{C}, \sigma\right)_{\mathrm{i}}+\left(\mathrm{C}-\mathrm{C}_{\mathrm{m}}\right)_{\mathrm{i}}^{2}\right\} \\
s(y)=\min _{\sigma} y \sigma= \begin{cases}y \sigma_{\min } & \text { if } y>0 \\
y \sigma_{\max } & \text { if } y<0\end{cases}
\end{gathered}
$$

Since $s$ is nondifferentiable $H$ is also nondifferentiable. Using a regularized version of $s_{\delta}$ of $s$, defined as approximating $s(x)$ by

$$
\mathrm{s}_{\delta,[\mathrm{a}, \mathrm{b}]}(\mathrm{x})=\mathrm{x} \frac{\mathrm{b}-\mathrm{a}}{2}-\frac{\mathrm{b}+\mathrm{a}}{2} \int_{0}^{\mathrm{x}} \tan \mathrm{h}(\mathrm{y} / \delta) \mathrm{dy}, \delta>0 .
$$

and the derivative of $s_{\delta}$ by

$$
\mathrm{s}_{\delta,[\mathrm{a}, \mathrm{b}]}(\mathrm{x})=\frac{\mathrm{b}-\mathrm{a}}{2}-\frac{\mathrm{b}+\mathrm{a}}{2} \tan \mathrm{h}(\mathrm{x} / \delta)
$$

we can have the regularization of the Hamiltonian where $H$ becomes

$$
\mathrm{H}^{\delta}(\lambda, \mathrm{C})=\Delta \mathrm{K} \sum_{\mathrm{i}=1}^{\mathrm{M}-1}\left\{\mathrm{~s}_{\delta}\left(\lambda, \mathrm{D}^{1} \mathrm{C}, \mathrm{D}^{2} \mathrm{C}, \sigma\right)_{i}+\left(\mathrm{C}-\mathrm{C}_{\mathrm{m}}\right)_{\mathrm{i}}^{2}\right\}
$$

Let's have a uniform partition of the time interval $[0, \hat{\mathrm{T}}]$ with $\Delta \mathrm{t}=\hat{\mathrm{T}} / \mathrm{N}$ for some integer $N$. Again we introduce a uniform grid on $[0, \hat{\mathrm{K}}], \Delta \mathrm{K}=\hat{\mathrm{K}} / \mathrm{M}$, We use the notation

$$
\mathrm{C}_{\mathrm{i}}^{(\mathrm{j})}=\mathrm{C}(\mathrm{i} \Delta \mathrm{K}, \mathrm{j} \Delta \mathrm{T}) \lambda_{\mathrm{i}}^{(\mathrm{j})}=\lambda(\mathrm{i} \Delta \mathrm{K}, \mathrm{j} \Delta \mathrm{T})
$$

Let's write $\quad \mathrm{C}^{(\mathrm{j})}(\mathrm{K})=\mathrm{C}(\mathrm{K}, \mathrm{j} \Delta \mathrm{T}) \quad$ and $\lambda^{(\mathrm{j})}(\mathrm{K})=\lambda(\mathrm{K}, \mathrm{j} \Delta \mathrm{T})$ and assume that they satisfy a symplectic implicit Euler scheme (Sandberg and Szepessy 2006):

$$
\begin{aligned}
& \mathrm{C}^{(\mathrm{j}+1)}-\mathrm{C}^{(\mathrm{j})}=\Delta \mathrm{TH}_{\lambda}^{\delta}(\mathrm{C}, \lambda)^{(\mathrm{j})} \\
& \lambda^{(\mathrm{j})}-\lambda^{(\mathrm{j}+1)}=\Delta \mathrm{TH}_{\mathrm{C}}^{\delta}(\mathrm{C}, \lambda)^{(\mathrm{j})}
\end{aligned}
$$

where $H^{\delta}(C, \lambda)^{(j)}=H^{\delta}\left(C^{(j)}, \lambda^{(j+1)}\right)$.

\section{Convergence of Euler Pontryagin Approximation}

If the Hamiltonian in (15) is Lipschitz on $\mathrm{R}^{\mathrm{d}} \times \mathrm{R}^{\mathrm{d}}$, if (18) has a solution and $\lambda^{(j+1)}$ has uniformly bounded variation with respect to $\mathrm{C}^{(\mathrm{j})}$ for all $j$ and $\Delta \mathrm{T}$ then the optimal solution to the Pontryagin problem (18) $\left(C^{(j)}, \lambda^{(j)}\right)$ satisfies the error estimate (for $\delta \sim \Delta T$ )

$$
\left|\begin{array}{c}
\inf \int_{0}^{\hat{T}} \int_{\mathrm{R}+}\left(\mathrm{C}-\mathrm{C}_{\mathrm{m}}\right)^{2} \mathrm{dKdT}- \\
\Delta \mathrm{T} \sum_{\mathrm{j}} \int_{\mathrm{R}_{+}}\left(\mathrm{C}^{(\mathrm{j})}-\mathrm{C}_{\mathrm{m}}^{(\mathrm{j})}\right)^{2} \mathrm{dK}
\end{array}\right|=\mathrm{O}(\Delta \mathrm{T})
$$

For a proof see (Sandberg and Szepessy 2006).

Finally we summarize the above and obtain the completely discretized Hamiltonian system

$$
\begin{gathered}
\mathrm{C}_{\mathrm{i}}^{(\mathrm{j}+1)}-\mathrm{C}_{\mathrm{i}}^{(\mathrm{j})}=\Delta \mathrm{TH}_{\lambda}^{\delta}(\mathrm{C}, \lambda)_{\mathrm{i}}^{(\mathrm{j})} \\
\lambda_{\mathrm{i}}^{(\mathrm{j})}-\lambda_{\mathrm{i}}^{(\mathrm{j}+1)}=\Delta \mathrm{TH}_{\mathrm{C}}^{\delta}(\mathrm{C}, \lambda)_{\mathrm{i}}(\mathrm{j}) \\
\lambda_{M}^{(j)}=0 \quad \lambda_{0}^{(j)}=0 \lambda_{i}^{(N)}=0 C_{M}^{(j)}=0 C_{0}^{(j)}=S
\end{gathered}
$$

This discretization is very suitable for Newton like iterations.

\section{Control Approach to Algorithmic Trading}

Algorithmic Trading Control Problem as Viscosity Solution

The value function is defined on

$$
\begin{gathered}
\mathrm{D}:=\left\{(\mathrm{t}, \mathrm{x}, \delta, \mathrm{e}) \in[0, \mathrm{~T}) \times \mathrm{R}^{\mathrm{d}} \times(((0, \infty) \times \mathrm{E}) \cup\{(0, \varpi)\}):\right. \\
\underline{\delta} \leq \mathrm{t}+\delta<\mathrm{T} \text { or } \mathrm{e}=\varpi\} .
\end{gathered}
$$

which can be decomposed in two main regions. (a) the active region, the region where $\delta>0$ and $\mathrm{e} \neq \omega$ : It corresponds to the set of initial conditions where the algorithm is running and the controller has to wait till the end of the latency period before passing a new order. and (b) passive region, the region where $e=\varpi$, and therefore $\delta=0$.

$$
\mathrm{D}_{\varpi}:=[0, \mathrm{~T}) \times \mathrm{R}^{\mathrm{d}} \times\{(0, \varpi)\} .
$$


It corresponds to the set of initial conditions where the algorithm is running and can be launched immediately with a new set of parameters. These two regions are complemented by the natural boundaries of the active region when $\delta \rightarrow 0$ and $t+\delta \rightarrow T$ :

$$
D_{E, 0}:=[\underline{\delta}, T) \times R^{d} \times\{0\} \times E
$$

$D_{E, 0}:=\left\{(t . x, \delta . e) \in[0, T) \times R^{d} \times(0, \infty) \times E: \underline{\delta} \leq t+\delta=T\right\}$,

and by the boundary:

$$
D_{T}:=\{T\} \times R^{d} \times R_{+} \times \bar{E} .
$$

The closure of the natural domain of definition of the value function $V$ is therefore

$$
\begin{gathered}
\bar{D}:=\left\{(t, x, \delta, e) \in[0, T] \times R^{d} \times R_{+} \times \bar{E}: \underline{\delta} \leq t+\delta=T\right. \text { or } \\
e=\varpi\} .
\end{gathered}
$$

With dynamic programming principle, we can arrive at nature of the value function on each component of $\bar{D}$ :

$$
\begin{aligned}
& V(t, x, \delta, \varepsilon) \\
& =\sup _{v \in S_{t, \delta, e}^{a}} E\left[V\left(\vartheta, X_{t, x}^{v}(\vartheta), \Delta_{\vartheta}^{v}, v_{\vartheta}\right)+\sum_{i \in I_{t, \vartheta}^{v}} f\left(X_{t, x}^{v}\left(\tau_{i}^{v}+\delta_{i}^{v}\right), \varepsilon_{i}^{v}\right)\right],
\end{aligned}
$$

for any $[t, T]$-valued stopped time $\vartheta$.

For $(t, x, \delta, e) \in D_{E,>0}$, the controller can not change the parameter of the algorithm before the end of the initial latency period $\delta>0$. Choosing $\vartheta$ arbitrary small implies that $V$ should satisfy

$$
\left(-L^{\varepsilon}+\frac{\partial}{\partial \delta}\right) V(t, x, \delta, \varepsilon)=0,
$$

where $(t, x) \mapsto L^{e}+V(t, x, \delta, e)$ is defined for $(\delta, e)$ taken as parameters.

The boundary condition is

$V(t, x, \delta, e)=V(t, x, 0, \varpi)+f(x, e)$, if $(t, x, \delta, e) \in D_{E, 0}$,

and

$V(t, x, \delta, e)=V(t, x, e)$, if $(t, x, \delta, e) \in D_{T}$,

Boundary condition as $t \rightarrow T$ is the terminal condition:

$V(t, x, \delta, e)=g(x)+f(x, e)$, if $(t, x, \delta, e) \in D_{T}$,

where $f(\cdot, \varpi)=0$ by condition.

The above discussion shows that $V$ should solve the equation

$$
H \varphi=0
$$

on $\bar{D}$, where, for a smooth function $\varphi$ defined on $\bar{D}$,

$$
H=\left(-L^{\varepsilon}+\frac{\partial}{d \partial}\right) \phi(t, x, \delta, e) \quad \text { on } \quad D_{E,>0}
$$

However, since $V$ may not be smooth, it has to be stated in terms of viscosity solutions in the sense of Crandall Lions. See (Bouchard and Touzi 2009; Bouchard et al. 2010; Yong and Zhou 1999) for more details.

\section{NUMERICAL ALGORITHMS}

\section{Volatility Calibration}

$$
\begin{gathered}
\text { Let's } \begin{array}{c}
\text { introduce } \\
\mathrm{F}^{\delta}, \mathrm{G}^{\delta}: \mathrm{R}^{\mathrm{MN}} \rightarrow \mathrm{R}^{\mathrm{MN}}:
\end{array} \\
\mathrm{F}^{\delta}(\mathrm{C}, \lambda)_{\mathrm{i}+\mathrm{j}^{*} \mathrm{~N}}=\mathrm{C}_{\mathrm{i}}^{(\mathrm{j}+1)}-\mathrm{C}_{\mathrm{i}}^{(\mathrm{j})}-\Delta \mathrm{TH}_{\lambda, \mathrm{ij}}^{\delta} \\
\mathrm{G}^{\delta}(\mathrm{C}, \lambda)_{\mathrm{i}+\mathrm{j}^{*} \mathrm{~N}}=\mathrm{C}_{\mathrm{i}}^{(\mathrm{j})}-\mathrm{C}_{\mathrm{i}}^{(\mathrm{j}+1)}-\Delta \mathrm{TH}_{\mathrm{C}, \mathrm{ij}}^{\delta} .
\end{gathered}
$$

We need $(C, \lambda)$ such that $F^{\delta}(C, \lambda)=G^{\delta}(C, \lambda)=0$. Starting with some initial guess $(C[0], \lambda[0])$, the Newton method gives

$$
\left(\begin{array}{l}
\mathrm{C}[\mathrm{k}+1] \\
\lambda[\mathrm{k}+1]
\end{array}\right)=\left(\begin{array}{l}
\mathrm{C}[\mathrm{k}] \\
\lambda[\mathrm{k}]
\end{array}\right)-\left(\begin{array}{c}
\mathrm{X}[\mathrm{k}] \\
\mathrm{Y}[\mathrm{k}]
\end{array}\right) .
$$

where $(X[k], Y[k])$ is the solution to the following system of linear equations

$$
\mathrm{J}_{\mathrm{k}}\left(\begin{array}{c}
\mathrm{X}[\mathrm{k}] \\
\mathrm{Y}[\mathrm{k}]
\end{array}\right)=\left(\begin{array}{c}
\mathrm{F}(\mathrm{C}[\mathrm{k}], \lambda[\mathrm{k}]) \\
\mathrm{G}(\mathrm{C}[\mathrm{k}], \lambda[\mathrm{k}])
\end{array}\right)
$$

where $J_{k}$ denotes the Jacobean of $(\mathrm{F}, \mathrm{G}): \mathrm{R}^{2 \mathrm{MN}} \rightarrow \mathrm{R}^{2 \mathrm{MN}} \quad$ evaluated at $(\mathrm{C}[\mathrm{k}], \lambda[\mathrm{k}])$. Depending upon the desired level of accuracy this iteration can be performed. For some applications of this iteration to volatility calibration see (Gatheral 2006; Kiessling 2010).

\section{Algorithmic Trading}

Lax Fredrich Scheme

We can use the viscosity solution of the problem:

$$
\partial_{\mathrm{t}} \mathrm{u}^{\varepsilon}+\partial_{\mathrm{x}} \mathrm{H}\left(\mathrm{u}^{\varepsilon}\right)=\varepsilon \partial_{\mathrm{xx}} \mathrm{u}^{\varepsilon} \text { for }(\mathrm{x}, \mathrm{t}) \in \mathrm{R} \times(0, \infty) .
$$

$$
u^{\varepsilon}(x, 0)=g(x) \text { for } x \in R .
$$

to construct solution to the following desired problem

$$
\begin{gathered}
\partial_{\mathrm{t}} \mathrm{u}+\partial_{\mathrm{x}} \mathrm{H}(\mathrm{u})=0 \text { for }(\mathrm{x}, \mathrm{t}) \in \mathrm{R} \times(0, \infty) . \\
\mathrm{u}(\mathrm{x}, 0)=\mathrm{g}(\mathrm{x}) \text { for } \mathrm{x} \in \mathrm{R} .
\end{gathered}
$$

for which the Lax Friedrich scheme (Sandberg and Szepessy 2006; Bouchaouv and Isakov 1997 ) is 


$$
u_{j}^{n+1}=u_{j}^{n}-\Delta t\left[\frac{H\left(u_{j+1}^{n}\right)-H\left(u_{j-1}^{n}\right)}{2 \Delta x}-\frac{(\Delta x)^{2}}{2 \Delta t} D_{+} D_{-} u_{j}^{n}\right]
$$

where

$$
\begin{gathered}
D_{+} V_{j}=\frac{V_{j+1}-V_{j}}{\Delta x}, D_{-} V_{j}=\frac{V_{j}-V_{j-1}}{\Delta x} \\
D_{+} D_{-} V_{j}=\frac{V_{j+i}-2 V_{j}+V_{j-1}}{(\Delta x)^{2}}
\end{gathered}
$$

The stability condition for above scheme is

$$
\lambda=\frac{\Delta \mathrm{x}}{\Delta \mathrm{t}}>\max _{\mathrm{u}}\left|\mathrm{H}^{\prime}(\mathrm{u})\right|
$$

In the two-dimensional case if a first order Hamilton-Jacobi equation has the form

$$
\partial_{\mathrm{t}} \mathrm{V}+\mathrm{H}\left(\partial_{\mathrm{x}} \mathrm{V}\right)=0
$$

The Lax Friedrich scheme for this two dimensional case is

$$
\begin{aligned}
\mathrm{V}_{\mathrm{j}, \mathrm{k}}^{\mathrm{n}+1}=\mathrm{V}_{\mathrm{j}, \mathrm{k}}^{\mathrm{n}}-\Delta \mathrm{t}[\mathrm{H} & \left(\frac{\mathrm{V}_{\mathrm{j}+1, \mathrm{k}}^{\mathrm{n}}-\mathrm{V}_{\mathrm{j}-1, \mathrm{k}}^{\mathrm{n}}}{2 \Delta \mathrm{x}_{1}}, \frac{\mathrm{V}_{\mathrm{j}, \mathrm{k}+1}^{\mathrm{n}}-\mathrm{V}_{\mathrm{j}, \mathrm{k}-1}^{\mathrm{n}}}{2 \Delta \mathrm{x}_{2}}\right) \\
& -\frac{\left(\Delta \mathrm{x}_{1}\right)^{2}}{4 \Delta \mathrm{t}} \frac{\mathrm{V}_{\mathrm{j}+1, \mathrm{k}}^{\mathrm{n}}-2 \mathrm{~V}_{\mathrm{j}, \mathrm{k}}^{\mathrm{n}}+\mathrm{V}_{\mathrm{j}-1, \mathrm{k}}^{\mathrm{n}}}{\left(\Delta \mathrm{x}_{1}\right)^{2}} \\
& -\frac{\left(\Delta \mathrm{x}_{2}\right)^{2}}{4 \Delta \mathrm{t}} \frac{\mathrm{V}_{\mathrm{j}, \mathrm{k}+1}^{\mathrm{n}}-2 \mathrm{~V}_{\mathrm{j}, \mathrm{k}}^{\mathrm{n}}+\mathrm{V}_{\mathrm{j}, \mathrm{k}-1}^{\mathrm{n}}}{\left(\Delta \mathrm{x}_{2}\right)^{2}}
\end{aligned}
$$

So for our problem which is a four dimensional case that scheme will finally reduce to finite difference schemes (Almgren 2009; Bouchard et al. 2010).

\section{CONCLUSION}

Inverse problems are ubiquitous in economics and finance, some examples are learning market neutral measure and volatility estimation etc. Control framework comes into picture as many problems can be transformed from original form into optimization problems for which dynamic programming or optimal control theory could be applied. Numerical discretization of these problems therefore become very important as they can be solved very efficiently for lower dimensional cases and these schemes are highly parallelizable which makes use of these numerical methods very attractive for problems with intensive computational needs.

\section{REFERENCES}

Achdou, Y. and O. Pironneau. Computational methods for option pricing, volume 30 of Frontiers in Applied
Mathematics. Society for Industrial and Applied Mathematics (SIAM), Philadelphia, PA, 2005. ISBN 089871- 573-3.

Andersen, L. and J Andreasen. "Jump-diffusion processes: Volatility smile fitting and numerical methods for option pricing. Review of Derivatives Research." 4(4):231-262, 2000.

Almgren, R. "Optimal trading in a dynamic market." Technical Report 2, 2009.

Bensoussan, A. and P.L. Lions. "Impulse control and quasivariational inequalities." Gauthier-Villars Paris, 1984

Bouchard, B. and N. Touzi. "Weak dynamic programming principle for viscosity solutions." Technical report, CEREMADE, 2009.

Bouchard, B., C.A. Lehalle and N.M. Dang. "Optimal control of trading algorithms: a general impulse control approach." SIAM Journal on Financial Mathematics. 2010

Bouchouev, I. and V. Isakov. "The inverse problem of option pricing." Inverse Problems, 13:L117, 1997

Cont, R. and P Tankov. Financial modeling with jump process. Chapman \& Hall/CRC Financial Mathematics Series. Chapman \& Hall/CRC, Boca Raton. FL. 2004.

Crandall, M.G., L. C. Evans. and P.-L. Lions. "Sonic properties of viscosity solutions of Hamilton Jacobi equations." Trans. Amer. Math. Soc., 282(2):487-502, 1984.

Dupire, B. "Pricing and hedging with smiles. In Mathematics of derivative securities." (Cambridge, 1995), volume 15 of Publ. Newton Inst., pages 103-111. Cambridge Univ. Press. Cambridge. 1997.

Gatheral, J. The volatility surface; A Practitioner's Guide. John Wiley \& Sons, Inc., 2006

Kiessling, J. "Approximation and calibration of stochastic processes in finance.” Doctoral Thesis 2010. KTH Royal Institute of Technology , Sweden http://www.math.kth.se/ jonkie/Introduction.pdf

Sandberg, M. "Extended applicability of the symplectic pontryagin method." arXiv:0901.4805v1.

Sandberg, M. and A Szepessy. "Convergence rates of symplectic Pontryagin approximations in optimal control theory." Math. Modd. Numer. Anal. 40(ID:149-173. 2006.

Yong, J. and X.Y. Zhou. Stochastic Controls Hamiltonian Systems and HJB equations. Springer Verlag 1999.

\section{AUTHOR BIOGRAPHY}

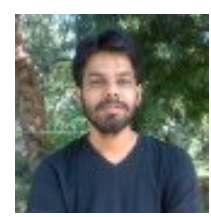

DEEPAK KUMAR was born in Bihar, India and is currently in his final year of Masters in Economics at Indian Institute of Technology Kanpur, India. He is interested in mathematical finance and believes that economics fraternity can learn a lot from the approach of financial engineering for better comprehension of theory and offering better solutions. His e-mail address is : kdeepakeittk.ac.in, kdeepak.iitk@gmail.com. His webpage is https://sites.google.com/site/kdeepakiitk 